\title{
Injectable semi rigid penile prosthesis: study in rabbits and future perspectives
}

\author{
Salvador Vilar Correia Lima ${ }^{1}$, Humberto Montoro Chagas ${ }^{2}$, Caio Cesar Paes Monteiro ${ }^{3}$, \\ Rafaela Siqueira Ferraz-Carvalho $^{1 \wedge}$, Amanda Vasconcelos Albuquerque ${ }^{\wedge} \wedge$, Anderson Arnaldo Silva ${ }^{4}$, \\ Mariana Montenegro de Melo Lira ${ }^{5}$, Fábio Oliveira Vilar ${ }^{6}$
}

${ }^{1}$ Nucleus for Experimental Surgery, Post-graduate Program in Surgery, Department of Surgery, Health Sciences Center, Federal University of Pernambuco, Recife, Brazil; ${ }^{2}$ Department of urology, Federal University of Alagoas, Maceio, Brazil; ${ }^{3}$ Federal University of Pernambuco, Recife, Brazil; ${ }^{4}$ Departament of Anatomy, Biosciences Center, Federal University of Pernambuco, Recife, Brazil; ${ }^{5}$ Departament of Patology, Health Sciences Center, Federal University of Pernambuco, Recife, Brazil; ${ }^{6}$ Head of Urology Department, Federal University of Pernambuco, Recife, Brazil

Contributions: (I) Conception and design: SVC Lima, HM Chagas, FO Vilar; (II) Administrative support: None; (III) Provision of study materials or patients: SVC Lima, HM Chagas, FO Vilar; (IV) Collection and assembly of data: HM Chagas, CCP Monteiro, RS Ferraz-Carvalho, AV Albuquerque, AA Silva, MMM Lira; (V) Data analysis and interpretation: CCP Monteiro, RS Ferraz-Carvalho, AV Albuquerque, AA Silva, MMM Lira; (VI) Manuscript writing: All authors; (VII) Final approval of manuscript: All authors.

Correspondence to: Salvador Vilar Correia Lima. Department of Surgery, Center for Health Sciences, Federal University of Pernambuco, Recife, Brazil. Email: salvadorvilarcorreialima@gmail.com.

Background: Penile prostheses are the third option in the treatment of erectile dysfunction, however, despite their proven effectiveness, the occurrence of infections, advanced age of patients and comorbidities are the main limiting factors for this treatment modality. In the continuous search for biointegrated, clinically durable and minimally invasive treatment options, a possible model of penile prosthesis was sought through the use of intracavernous bacterial cellulose (BC) gel, in an experimental model of orchiectomized rabbits.

Methods: Thirty adult New Zealand rabbits were equally distributed into three groups: BC; vehicle and control. Each group was then subdivided according to the follow-up time of 3 and 6 months. Bilateral orchiectomy was performed 3 weeks before injection in the BC and vehicle groups. Pachymetry measurements of the penile axis, diameter and length were performed in situ. Histomorphometry analyzes of the corpora cavernosa (CC), thickness of the tunica albuginea, cell density, collagen and elastic fibers postinjection were also performed, in addition to immunohistochemistry for newly formed vessels.

Results: The implant of BC increased both the length and thickness of the penis three and six months after the last injection, with a consequent increase in the diameter of the CC. On the other hand, the filling effect was not observed in the control and vehicle groups, confirming the degradation of this tissue after orchiectomy and the effectiveness of $\mathrm{BC}$ as a filling agent. Histomorphometry analyzes corroborate the mass effect of BC integrated into the tissue, permeated by predominantly lymphomononuclear inflammatory infiltrate, multinucleated giant foreign body cells, fibroblasts, elastic fibers and newly formed vessels, without degradation or loss of volume, even after six months of implantation.

Conclusions: Biocompatibility and biointegration to the host tissue make BC a prosperous penile filling material, with local application and minimally invasive.

Keywords: Erectile dysfunction; biopolymer; bacterial cellulose (BC); penile prosthesis

Submitted Jul 29, 2020. Accepted for publication Dec 22, 2020.

doi: $10.21037 /$ tau-20-1128

View this article at: http://dx.doi.org/10.21037/tau-20-1128

^ ORCID: Rafaela Siqueira Ferraz-Carvalho, 0000-0002-3883-6474; Amanda Vasconcelos Albuquerque, 0000-0002-7473-0116. 


\section{Introduction}

The penile prosthesis implant is the third line of treatment for erectile dysfunction and is indicated for patients who do not improve with pharmacotherapy, especially with oral phosphodiesterase-5 (PDE-5) inhibitors, or who prefer a permanent treatment modality. The available classes of penile implants include inflatable and malleable (2- and 3 -piece) or semi-rigid prostheses $(1,2)$.

Although they have a high rate of satisfaction $(92-100 \%$ of patients, $91-95 \%$ of partners), as it is an invasive procedure, it has some disadvantages, such as irreversible change in penile body tissue after implantation with the destruction of cavernous tissue, moderate pain between 1 and 2 weeks after surgery, sexual intercourse after 6-8 weeks and complication rate of $2 \%$ to $10 \%$, mainly due to infection, extrusion of the prosthesis or failure of the erectile device of inflatable penile prostheses (2-6).

Filling agents are currently applied in different subareas of Medicine such as aesthetics, ophthalmology, plastic surgery, urology, proctology, among others. The use of bacterial cellulose (BC) gel using sugarcane molasses as substrate is based on numerous preclinical studies demonstrating that it is a stable polymer and is not absorbed by the surrounding tissues (7). It has low genotoxicity and cytotoxicity in vitro studies (8), high biocompatibility and integration in an in vivo model of gutted eyes (9); treatments for vesicoureteral reflux (10) and fecal incontinence (11). When comparing the $\mathrm{BC}$ gel implant to Deflux ${ }^{\circledR}$ by endoscopy directly below the bladder neck, there was no inflammatory reaction and in the longterm better tissue integration (10). Much of the therapeutic knowledge acquired in the area of biomaterials is related to morphological and pharmacological studies conducted in experimental models using rodents and rabbits, the latter being the most common non-rodent model in research for the treatment of erectile dysfunction (12) or for tissue engineering approaches, including phallic reconstruction $(13,14)$. Due to the scarcity of autologous tissues and the unique anatomical architecture of the corpora cavernosa (CC), these surgical procedures often use non-genital tissues as a graft source. Therefore, the creation of alternative materials that assist in the reconstruction of the $\mathrm{CC}$ becomes a great challenge for the Urologist, because in addition to the treatment for erectile dysfunction these filling agents can also be used in cases of congenital malformation, malignancy or trauma. Given the above, the main goal of this research was to translate basic science discoveries more quickly and efficiently into practice by intra-cavernous injection of $\mathrm{BC}$ gel using the rabbit as an experimental model to improve penile erections. We present the following article in accordance with the ARRIVE reporting checklist (available at http://dx.doi.org/10.21037/ tau-20-1128).

\section{Methods}

\section{Animals}

Experimental, prospective study using 30 rabbits adult males (Oryctolagus cuniculus), New Zealand lineage, weighing an average of $2.0 \mathrm{~kg}$. The animals were kept in individual's plastic cages and an appropriate environment with temperature and humidity control, day-night cycle artificially established for periods of 12 hours with access to water and food ad libitum. The calculation for determining the number of animals was based on Cochran's formula [1965], according to the confidence interval, standard deviation (SD) and the precision level of 0.05 (P value). The animals $(n=30)$ were randomly divided into three groups, with 10 animals per group, and named as follows: Bacterial cellulose gel group - BC; Vehicle Group - saline; Group control. Each group was then equally divided into two, according to the evaluation time of three and six months. Experiments were performed under a project license (No.: 23076.022494/2015-90) granted by Ethics Committee on the Use of Animals (CEUA) of the Federal University of Pernambuco (UFPE), in compliance with Ethics Committee national or institutional guidelines for the care and use of animals.

\section{Anesthesia and surgery}

The animals in the treated groups and vehicles were anesthetized by a veterinary in the morning, with Xylazine $(5 \mathrm{mg} / \mathrm{kg} \mathrm{IM})$ and Ketamine $(20 \mathrm{mg} / \mathrm{kg} \mathrm{IM})$. Ten minutes before the start of anesthesia, atropine sulfate was applied intramuscularly $(0.44 \mathrm{mg} / \mathrm{kg})$. The animals were kept with an oxygen mask $(0.5 \mathrm{~mL} / \mathrm{min})$ throughout the procedure. The animal was considered anesthetized with regular breathing and absence of reflexes after interdigital stimulus. The rabbits were placed in the supine position on the operating table (Figure 1), performing asepsis and antisepsis of the surgical field and positioning sterile fields. Orchiectomy was performed bilaterally in the treated and vehicle group, through a single supra-pubic incision of 

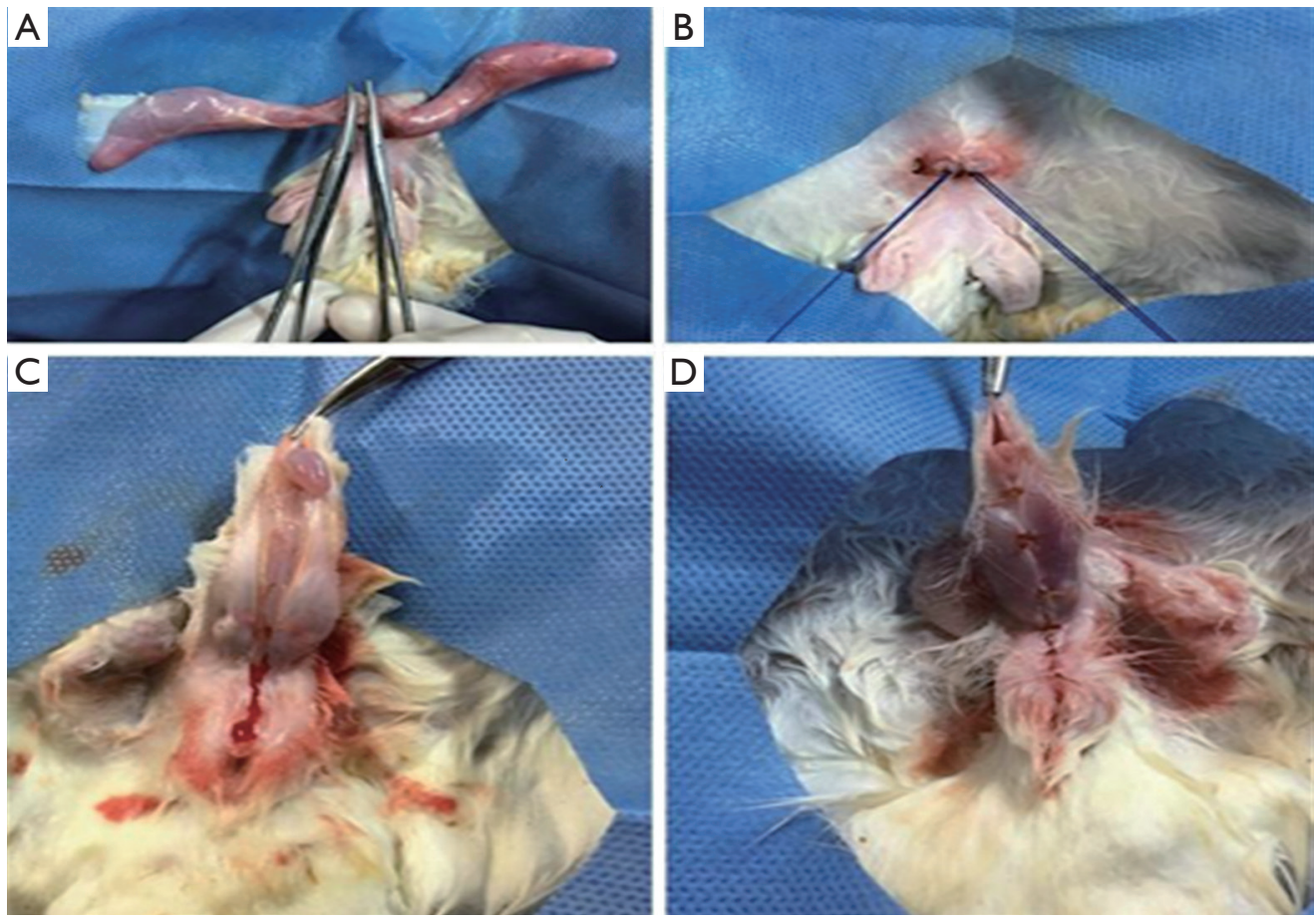

Figure 1 Surgical technique of orchiectomy (A,B) followed by release of the animal penile frenulum (C,D).

about $1 \mathrm{~cm}$, isolating the spermatic cord and pulling the testicles externally. Cord ligation was performed with 3-0 cotton thread. The body of the penis was released from its natural fold after local anesthesia with $2 \%$ lidocaine without adrenaline to its base, suturing the edges with 4-0 chrome catgut thread. The control group was not castrated, only the penis was detached from its natural fold, as mentioned above.

Three weeks after the orchiectomy, the animals in the experimental group received $1 \mathrm{~mL}$ of $\mathrm{BC}$ in each CC with a $26 \mathrm{G}$ needle, while the animals in the vehicle group received the same volume of saline. This procedure was performed 4 times with an interval of 1 week. The length and diameter of the penis of each animal were measured before and after each injection using a digital caliper (Figure 2).

\section{Sacrifice and sample collection}

At the end of three and six months, the animals were euthanized through intravenous administration of a lethal dose of sodium thiopental $(150 \mathrm{mg} / \mathrm{kg})$. The penis was then removed in its entirety by dissection, separating it from its point of attachment in the ischial tuberosity. The penis was weighed dry on an analytical balance and subsequently fixed by immersion in $10 \%$ formalin in $75 \mathrm{nM}$ phosphate buffer. Twenty four hours after fixation, the penis was cut into transverse fragments approximately $3-5 \mathrm{~mm}$ thick and postfixed in the same solution.

\section{Histological analysis}

All samples were processed routinely following the technique of dehydration in alcohol, diaphanization in xylene and inclusion in histological paraffin. $4 \mu \mathrm{m}$ thick slices were obtained, mounted on slides and later stained according to the study objective. The slides stained with Masson's trichrome were used to measure the thickness of the albugineous tunic and those stained with hematoxylin and eosin for the thickness of the CC and analysis of foreign body reaction and cell density. Finally, the Weigert's Resorcin Fuchsin technique was used to visualize the fibers of the elastic system. All photomicrographs were obtained using the AXIO microscope (Imager.M2m/Zeiss) attached to a camera (AXIOCam HRc/Zeiss) connected to the capture software ZEN 2 PRO (blue edition), ZEISS in 10, 20 and $40 \times$ objectives. 

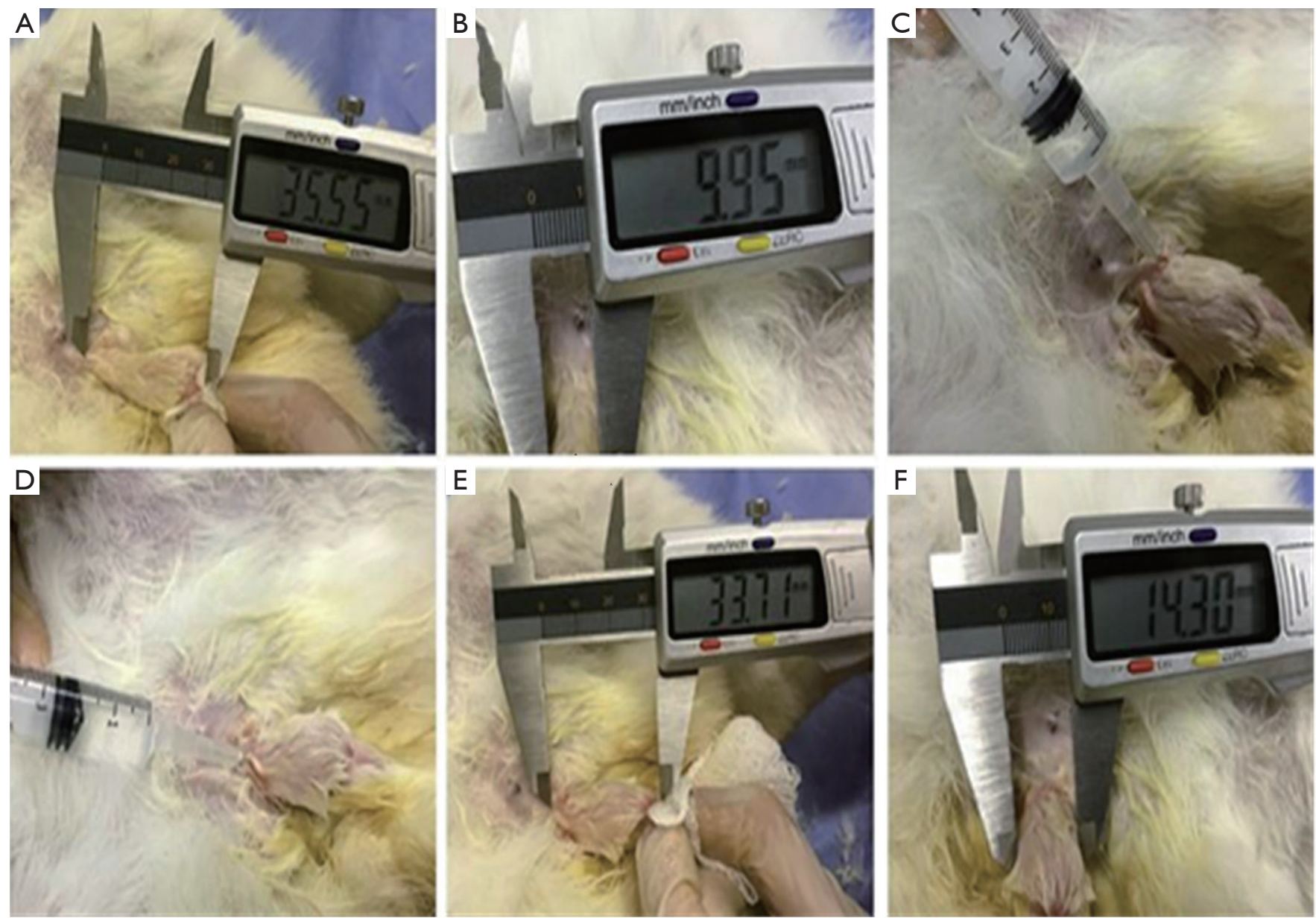

Figure 2 Pachymetry before injection of BC/saline, Penile length (A) and Penile diameter (B); injection of BC and saline (C/D) and pachymetry after injection of BC/saline, Penile length (E) and Penile diameter (F).

\section{Immunobistochemistry}

To identify the presence and specific location of newly formed blood vessels within the gel injected into the CC in $\mathrm{BC}$ groups three and six months, enzymatic antigenic recovery, elimination of endogenous peroxidase, blocking nonspecific antigens and immunohistochemical marking were conducted, using anti-CD31 antibody (Ab24590 monoclonal mouse Abcam; Lot 8065433; dilutions 1: 100). For antigenic recovery, trypsin solution $(0.01 \mathrm{~g}$ trypsin $+0.01 \mathrm{~g}$ calcium chloride $+10 \mathrm{~mL}$ distilled water) was used in a humid chamber, at $37^{\circ} \mathrm{C}$ for 30 minutes, and washed in three baths of PBS for $2 \mathrm{~min}$. The elimination of endogenous peroxidase was done in an alcoholic solution of hydrogen peroxide $(180 \mathrm{~mL}$ of methanol $+20 \mathrm{~mL}$ of $20 \%$ hydrogen peroxide) for $20 \mathrm{~min}$, at room temperature, protected from light, followed by washing in three baths with PBS, for 2 min each. To block nonspecific antigens from the tissue, a solution of skimmed milk diluted in $10 \%$ PBS for $30 \mathrm{~min}$ at room temperature was used. In the marking phase of the vessels, positive control (connective tissue of the animal), test and negative control (without primary antibody) were used. After washing in PBS, all slides (controls and test) were incubated with the secondary antibody in a humid chamber, for $20 \mathrm{~min}$ at $36^{\circ} \mathrm{C}$, following washes in PBS and incubation with reagent "C" for $15 \mathrm{~min}$, at $36^{\circ} \mathrm{C}$, and washes in PBS. The development of the antigen-antibody complex was performed with a diaminobenzidine solution (DAB, Histostar plus ${ }^{\circledR}$, Invitrogen ${ }^{\circledR}$ ), for 2 min. For nuclear contrast staining, Harris hematoxylin (diluted to $50 \%$ in distilled water) was used for $4 \mathrm{~min}$. Then the preparations followed the routine technique mentioned above to then be photographed. 


\section{Histomorphometry}

The diameter of the CC and the thickness of the tunica albuginea were obtained by averaging twenty measurements per corpus cavernosa, totaling 40 per animal. For this analysis, the Image J software was used, with the aid of the "straight line" tool, launched perpendicular to the direction of the fibers. Inflammatory tissue integration with foreign body reaction, cell density and vascular proliferation within the implanted material were quantified using the Image $\mathrm{J}$ software grid system. A mesh of 42 points was cast in each image obtained inside the cavernous bodies ( 15 per animal), totaling 630 points. Blood vessels, fibroblasts, foreign bodytype multinucleated giant cells (FBGC), macrophages, mononuclear and polymorphonuclear inflammatory cells and the presence of $\mathrm{BC}$ were quantified. At the end, the averages were obtained for each cell type or structure reached by the points, in addition to the SD.

\section{Statistical analysis}

Biometric and histomorphometry records were used to calculate the mean and SD values in each group. The Kolmogorov-Smirnov test was chosen to assess normal distribution. Analysis of variance was used to assess the effects of time and experimental conditions. To analyze the differences between the groups, the one-way ANOVA was performed followed by the Tukey post-hoc test. For analysis of parameter differences between 3 and 6 months postinjection, the variables of the normal curve were compared using the $t$-test, followed by the calculation of $\mathrm{P}$ values, considering values statistically significant $\leq 0.05$ ). For all analyzes, the SigmaStat 3.5 software was used.

\section{Results}

\section{Clinical aspects}

There were no complications in the intracavernous injection procedure in any of the groups. However, it was observed that in 3 animals of BC group the injected gel did not fill the corpora cavernousa in its entirety, and the penis showed a discontinuous filling of the material. The average surgical time for $\mathrm{BC}$ or saline injection was five minutes per animal. In general, animals showed an immediate erection response induced by $\mathrm{BC}$, with exposure of the glans after intracavernous injection (Figure 3). It was observed that after three months the animals were completely healed and after six months the penile rigidity was still palpable.

\section{Penile length and thickness "in situ"}

After intracavernous injection of the $\mathrm{BC}$, there was an increase in both penile length and diameter from $41.04 \pm 1.61$ to $49.96 \pm 0.68$ and from $13.95 \pm 0.38$ to $23.19 \pm 1.35$, respectively, after the six-month period (Table 1 ). This increase was maintained over the experimental time, without loss of volume when comparing the times of three and six months (Table 1). Rabbits that received BC showed a recovery in erectile function when compared to those that received saline injections.

\section{Bulking effect}

Histological analysis revealed the filling of the CC by BC with preservation of tissue constituents. Figure 4 shows the integrity of the spongy body and the preservation of the urothelium. The BC remains at the implantation site, after three and six months, causing a mass effect and being incorporated into the host tissue.

\section{Morphometry of the CC}

After the orchiectomy, significant differences were observed in the diameter of the $\mathrm{CC}$ of the penis, whether or not followed by filling with the $\mathrm{BC}$. As expected, there was a decrease in the diameter of the CC in the vehicle group, confirming the effects of the absence of androgens in the tissue, as well as an increase in the diameter after filling with the cellulose gel. The bulking effect again remained in the tissue, without resorption, even after six months of injection (Figure 5).

\section{Cell density and foreign body reaction}

The integration and biocompatibility of the BC after implantation were evaluated according to cellularity and neovascularization. The inflammatory response mediated by FBGC, lymphocytes, plasmocytes and polymorphonuclear cells remained unchanged over the experimental period, with a greater number of multinucleated giant cells of the foreign body type, blood vessels and fibroblasts after three months and a greater number of macrophages after six months (Table 2).

\section{Albugineous tunic, elastic fibers and newly formed vessels.}

The thickness of the albugineous tunic remained unchanged 

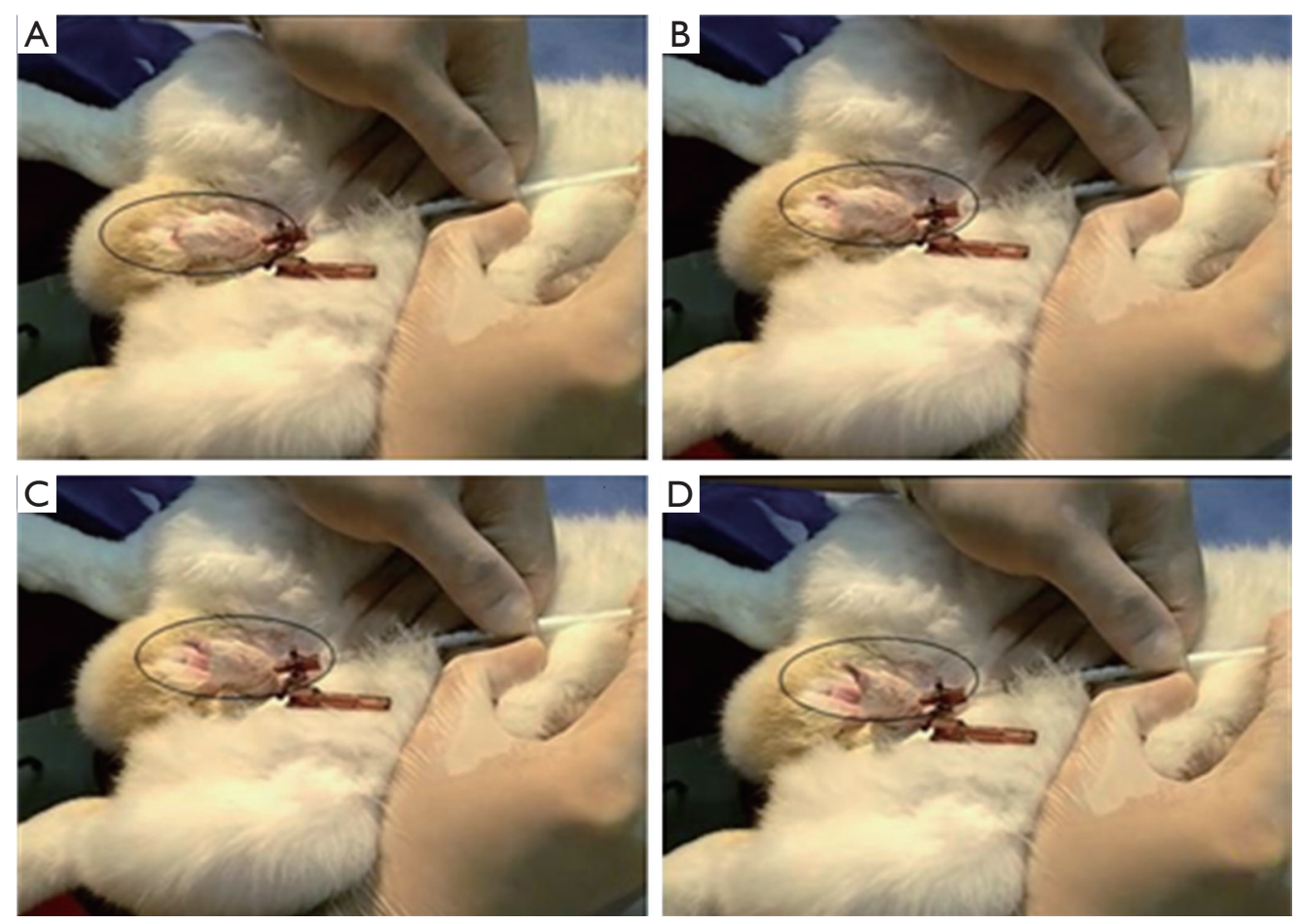

Figure 3 Gradual erection of the rabbit's penis after intracavernous BC injection (A,B,C) showing palpable penile rigidity in (D).

Table 1 Penile length and thickness after BC injection

\begin{tabular}{|c|c|c|c|c|c|c|}
\hline Groups & \multicolumn{3}{|c|}{ Penile length (mm) } & \multicolumn{3}{|c|}{ Penile diameter (mm) } \\
\hline Control & $31.90 \pm 1.30$ & $36.56 \pm 4.21$ & $41.04 \pm 1.61^{a}$ & $11.03 \pm 1.31$ & $14.15 \pm 0.60$ & $13.95 \pm 0.38^{a}$ \\
\hline Vehicle & $35.41 \pm 0.83$ & $35.56 \pm 1.14$ & $39.53 \pm 1.95^{a}$ & $14.59 \pm 0.68$ & $13.14 \pm 0.79$ & $14.93 \pm 0.79^{a}$ \\
\hline $\mathrm{BC}$ & $35.55 \pm 0.86$ & $36.04 \pm 0.87$ & $49.96 \pm 0.68^{b}$ & $11.03 \pm 1.31$ & $17.15 \pm 0.44$ & $23.19 \pm 1.35^{b}$ \\
\hline
\end{tabular}

Values presented as mean \pm standard error of the mean. Vehicle, saline; BC, bacterial cellulose gel. T0, T3m and T6m (experimental times before injections, after 3 and 6 months, respectively. Different letters in the same column $=\mathrm{P}<0.05$ after One-way ANOVA test.

in the vehicle group and was less thick in the BC group (Figure 6A). The colonization of BC in corpora cavernousa shows multinucleated giant cells of the foreign body type (Figure $6 B$ ) and fibroblasts. The deposition of elastic fibers increased over the experimental time, but without statistical differences regarding their deposition (Figure 6C). Vascularization of the implant was observed in both experimental times, with newly formed vessels located peripherally to the implant (Figure 6D).

\section{Discussion}

In recent years, there has been significant progress in understanding the multifactorial mechanisms that modulate and predispose to erectile dysfunction (15-19), leading to a greater demand for alternative treatment options especially through pre-clinical experimental models $(20,21)$. The results of the present study, although preliminary and preclinical, can be used in the future as a new idea for the treatment of erectile dysfunction. Because it is biocompatible, generating new blood vessels and remaining in the injected site, $\mathrm{BC}$ and any other substance provided have had tested can be used as a filling similar agent. Thus, patients who do not have sufficient hardness or stiffness for penetration or even patients who do not achieve the expected results using oral pharmacotherapy 

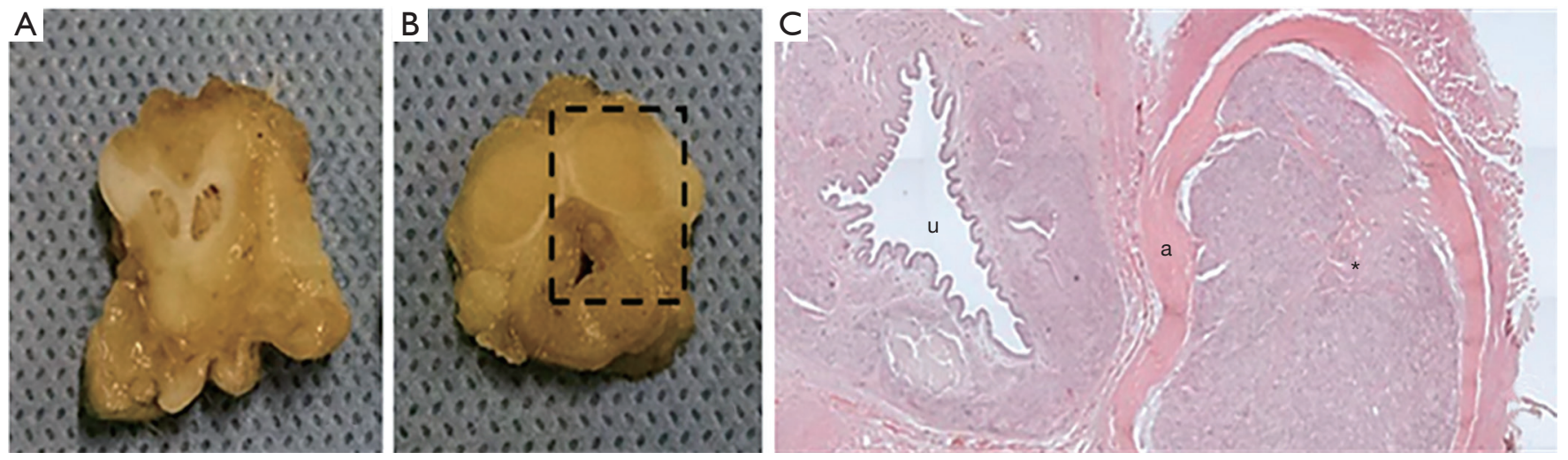

Figure 4 Sections of the penis after euthanasia of the vehicle (A) and BC (B) animals after 6 months. In (C) there is a photomicrograph of the panoramic section of the cavernous bodies stained with HE, completely filled with BC, surrounded by the white tunic and with preservation of the spongy body and urothelium. Caption u, urethra; a, tunic albuginea. *, bacterial cellulose.

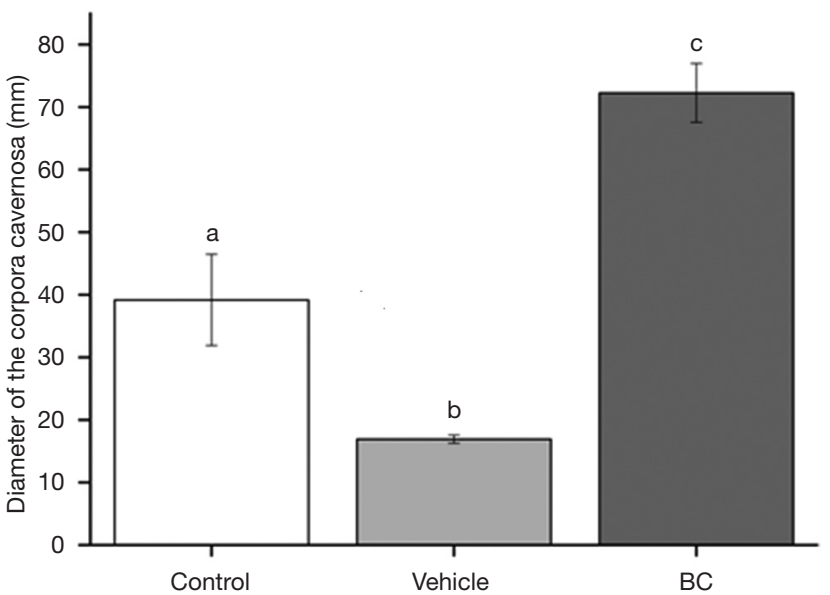

Figure 5 Diameter of the corpora cavernosa between the control groups; vehicle: saline and bacterial cellulose gel after 6 months of implantation. Values tested for normality. Different letters = statistical differences after One-way ANOVA.

[e.g., men with diabetes mellitus (DM) or with erectile dysfunction after radical prostatectomy] may use it in the future the $\mathrm{BC}$ gel in combination with another treatment. The idea is that depending on the intracavernous volume injected from the $\mathrm{BC}$, the penis may become more rigid or less rigid and this in association with oral drugs in the form of phosphodiesterase type 5 (PDE5i) inhibitors or intracavernous injection with vasodilating agents may enhance the erection for successful penetration.

Penile prostheses, although having a high satisfaction rate, have as possible complications the irreversible change of the penile structure, pain, infections, extrusions or failures in the device (4). In tissue engineering, including phallic reconstruction $(13,14)$ due to the scarcity of autologous tissues and the unique anatomical architecture of the CC, these surgical procedures often use non-genital tissues as a graft source. The use of BC gel was then used as a filling agent for the CC, obtained from the molasses of sugar cane, a sterile, stable, non-toxic and biointegrated polymer $(7,8,11)$. The clinical and morphological findings of anatomical filling of the cavernous body (bulking effect) and permanence of the material in situ were considered promising. No complications were observed, such as hypersensitivity or extrusion, there was a significant increase in penile volume, in length and thickness, in addition to palpable stiffness, essential characteristics of a good prosthesis (22). Using the same animal model, other studies have not observed signs of infection or extrusion of the prosthesis (9), in addition to a better inflammatory response and preservation of the injected material when compared to another biodegradable gel commonly used in urology to treat vesicoureteral reflux10. However, we observed a discontinuous filling of the material what could be avoided by recalculating the ideal volume to be injected into the animal's penis.

The atrophy of the CC was induced in this study through surgical castration, due to androgen deficiency (23), with a significant decrease in the diameter of this tissue below the control values, corroborating with a previous study that demonstrated the loss of erectile function and penile atrophy, with reduced trabecular smooth muscle and increased connective tissue content (24). Histological and 
Table 2 Inflammatory response and neovascularization of the BC implant

\begin{tabular}{lccccccc}
\hline Groups & BS (\%) & Fib (\%) & MNGC (\%) & Mac (\%) & Mono (\%) & Poli (\%) & CG (\%) \\
\hline BC-3m & $46.50(2.1)$ & $82.25(13.0)$ & $126.25(20.0)$ & $84(13.3)$ & $19.75(3.1)$ & $0.75(0.12)$ & $303.75(48.2)$ \\
BC-6m & $20.80(0.5)$ & $23.4(3.7)$ & $87.4(13.8)$ & $185.4(29.4)$ & $12.4(1.9)$ & $0.2(0.03)$ & $318(50.4)$ \\
P-value & 0.042 & 0.001 & 0.137 & 0.025 & 0.132 & 0.413 & 0.772 \\
\hline
\end{tabular}

Values presented as average (\%) in a total of 630 points counted (100\%). P-thanks: test t. BS, blood vessel; Fib, fibroblasts, MNGC, multinucleated giant cells; Mac, macrophages; Mono, mononuclear leukocytes; Poli, polymorphonuclear leukocytes; CG, cellulose gel.
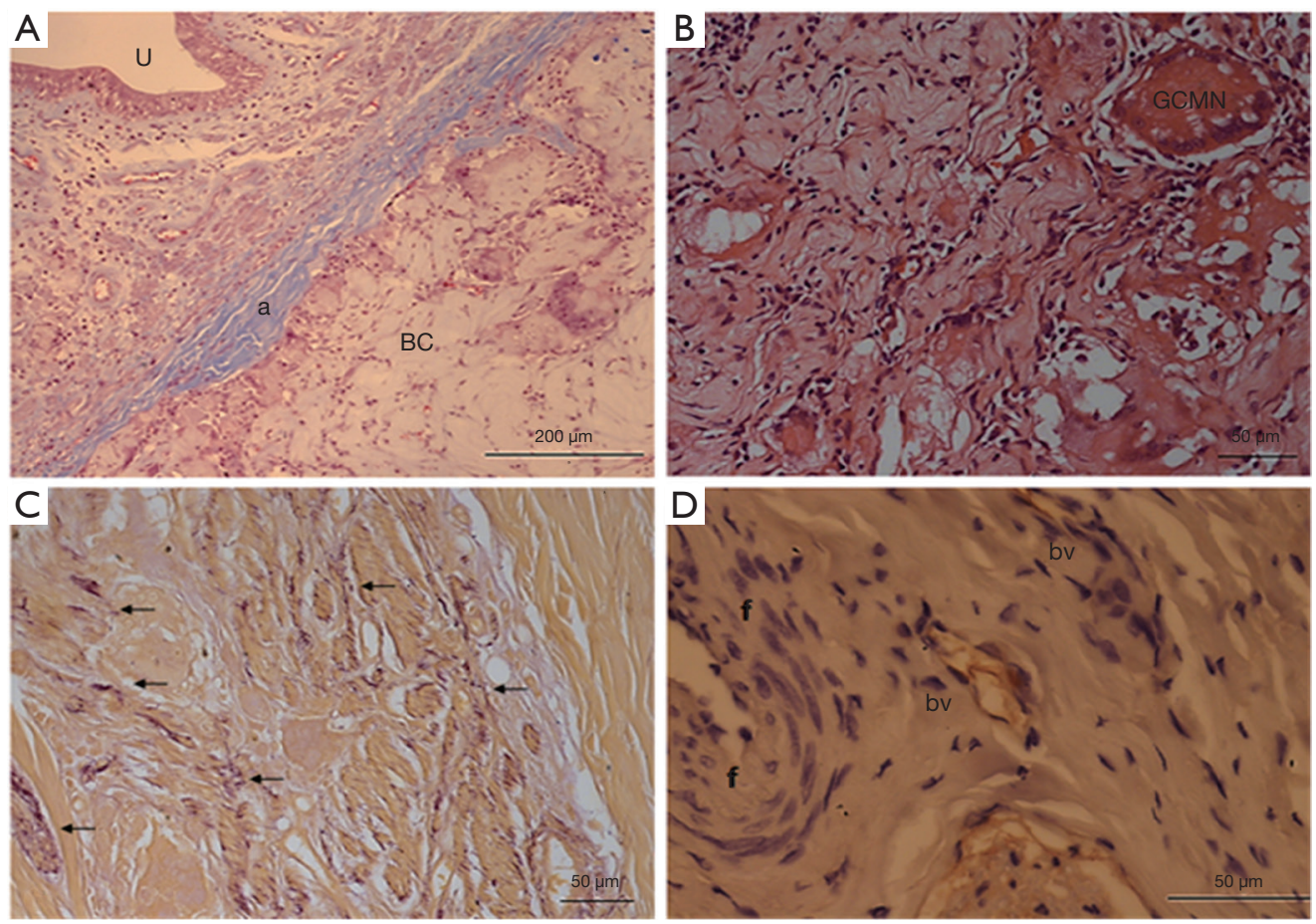

Figure 6 Photomicrographs inside the cavernous body filled with BC gel after 6 months of implant showing the integrity of the albuginous tunic and urothelium (A), integrated into the tissue with giant multinuclear cells (B), deposition of elastic fibers (C) and vessels neoformed blood cells (D). U, urothelium; a, white tunic; BC, bacterial cellulose; GCMN, multinucleated giant cell; arrows, elastic fibers; f, fibroblasts; bv, blood vessels.

morphometric analysis revealed the filling of the CC by the BC with preservation of tissue constituents, especially urothelial cells, with an increase in the thickness of the CC, as well as a decrease in the thickness of the albugineous tunica. The BC remained "in situ" after six months, with a mass effect, being incorporated into the tissue, permeated by normal inflammatory infiltrate. The volumetric density of the constituents revealed the predominance of macrophages and multinucleated giant cells of the foreign body type, in addition to fibroblasts and blood vessels, a process expected after the injection of any exogenous material in the body $(25,26)$. Histochemistry technique, demonstrated the presence of elastic fibers, essential for the elasticity of erectile tissue (26) and after immunohistochemistry the presence of neoformed blood vessels, of small caliber, located peripherally to the implant, corroborating the tissue biocompatibility observed in previous studies using the same cellulose bacteria $(9,11)$. Following blood-material interactions, platelets and the clot release chemoattractant that can direct macrophages to the wound site (27). Once at the implant surface, the macrophages can then adhere and engage in the subsequent events of the foreign body 
reaction. An understanding of this event is important as the foreign body reaction may impact the biocompatibility of the prosthesis and may significantly impact short- and long-term tissue responses for use in tissue engineering and translational medicine.

The BC gel implanted "in vivo", acted as a tissue framework of erectile tissue, allowed cell growth, with the formation of blood capillaries peripherally in the $\mathrm{CC}$ and enabled the deposition of extracellular matrix constituents such as elastic fibers, without addition of any growth factor. BC using sugarcane molasses as a substrate resembles biodegradable polymeric structures and can be useful for creating autologous penile prostheses. The use of injectable $\mathrm{BC}$ prostheses may be applied in the future to patients undergoing penile surgery for congenital or acquired conditions, for cases of penile reconstruction or for erectile dysfunction. The present study could be strengthened adding BC or other bulking agents as an injectable prosthesis in clinical tests. Additional studies must be carried out, including the establishment of functional and biomechanical parameters of the prosthesis in vivo and that are currently underway in our laboratory.

\section{Conclusions}

The biocompatibility and biointegration to the host tissue make BC a prosperous penile filling material. We include recommendations on future biomechanical approaches, and novel implant designs using $\mathrm{BC}$ that may revolutionize the future management of ED.

\section{Acknowledgments}

POLISA- Biopolymers for health. Incubated Company, Federal Rural of Pernambuco- Recife, Brazil provided the material injected for the BC group. The research was performed in collaboration with Department of Nuclear Energy (DEN), Immunopathological Laboratory Keizo Asami (LIKA) both from Federal University of Pernambuco (UFPE, Recife/PE, Brazil) and Pernambuco Science and Technology Support Foundation (FACEPE).

Funding: None.

\section{Footnote}

Reporting Checklist: The authors have completed the ARRIVE reporting checklist. Available at http://dx.doi. org/10.21037/tau-20-1128
Data Sharing Statement: Available at http://dx.doi. org/10.21037/tau-20-1128

Conflicts of Interest: All authors have completed the ICMJE uniform disclosure form (available at http://dx.doi. org/10.21037/tau-20-1128). The authors have no conflicts of interest to declare.

Ethical Statement: The authors are accountable for all aspects of the work in ensuring that questions related to the accuracy or integrity of any part of the work are appropriately investigated and resolved. Experiments were performed under a project license (No.: 23076.022494/201590) granted by Ethics Committee on the Use of Animals (CEUA) of the Federal University of Pernambuco (UFPE), in compliance with Ethics Committee national or institutional guidelines for the care and use of animals.

Open Access Statement: This is an Open Access article distributed in accordance with the Creative Commons Attribution-NonCommercial-NoDerivs 4.0 International License (CC BY-NC-ND 4.0), which permits the noncommercial replication and distribution of the article with the strict proviso that no changes or edits are made and the original work is properly cited (including links to both the formal publication through the relevant DOI and the license). See: https://creativecommons.org/licenses/by-nc-nd/4.0/.

\section{References}

1. Shamloul R; Ghanem H. Erectile Dysfunction. Lancet 2013;381:153-65.

2. Burnett AL, Nehra A, Breau RH, et al. Erectile Dysfunction: AUA Guideline. J Urol 2018;200:633-41.

3. Bella AJ, Lee JC, Carrier S, et al. CUA Practice guidelines for erectile dysfunction. Can Urol Assoc J 2015;9:23-9.

4. Mahon J, Dornbier R, Wegrzyn G, et al. Infectious Adverse Events Following the Placement of a Penile Prosthesis: A Systematic Review. Sex Med Rev 2020;8:348-54.

5. Campbell JD, Milenkovic U, Albersen M, et al. What Is the Future of Erectile Dysfunction Therapy? Curr Sex Health Rep 2018;10:169-76.

6. Krzastek SC, Bopp J, Smith RP, et al. Recent advances in the understanding and management of erectile dysfunction. F1000Res 2019;8:1-8.

7. Paterson-Beedle M, Kennedy JF, Melo FA, et al. A cellulosic exopolysaccharide produced from sugarcane 
molasses by a Zoogloea sp. Carbohydr Polym 2000;42:375-83.

8. Pinto FCM, De-Oliveira ACA, De-Carvalho RR, et al. Acute toxicity, cytotoxicity, genotoxicity and antigenotoxic effects of a cellulosic exopolysaccharide obtained from sugarcane molasses. Carbohydr Polym 2016;137:556-60.

9. Cordeiro-Barbosa FDA, Aguiar JLDA, Lira MMDM, et al. Use of a gel biopolymer for the treatment of eviscerated eyes: experimental model in rabbits. Arq Bras Oftalmol 2012;75:267-72.

10. Lima SVC, Rangel AEO, Lira MMM, et al. The Biocompatibility of a Cellulose Exopolysaccharide Implant in the Rabbit Bladder When Compared With Dextranomer Microspheres Plus Hyaluronic Acid. Urol 2015;85:1520-e1.

11. Cavalcante ART, Lima RP, Souza VSB, et al. Effects of bacterial cellulose gel on the anorectal resting pressures in rats submitted to anal sphincter injury. Heliyon 2018;4:e01058.

12. Williams JK, Andersson KE, Christ G. Animal models of erectile dysfunction (ED): potential utility of non-human primates as a model of atherosclerosis-induced vascular ED. Int J Impot Res 2012;24:91-100.

13. Yoo JJ, Park HJ, Atala A. Tissue-engineering applications for phallic reconstruction. World J Urol 2000;18:62-6.

14. Falke G. Yoo JJ, Kwon TG, et al. Formation of corporal tissue architecture in vivo using human cavernosal muscle and endothelial cells seeded on collagen matrices. Tissue Eng 2003;9:871-9.

15. Costabile RA. Optimizing treatment for diabetes mellitus induced erectile dysfunction. J Urol 2003;170:S35-8.

16. De Berardis G, Pellegrini F, Franciosi M, et al. Identifying patients with type 2 diabetes with a higher likelihood of erectile dysfunction: the role of the interaction between clinical and psychological factors. J Urol 2003;169:1422-8.
17. Burchardt M, Burchardt T, Baer L, et al. Hypertension is associated with severe erectile dysfunction. J Urol 2000;164:1188-91.

18. Goldstein I. The mutually reinforcing triad of depressive symptoms, cardiovascular disease, and erectile dysfunction. Am J Cardiol 2000;86:41F-5F.

19. Kawanishi Y, Lee KS, Kimura K, et al. Screening of ischemic heart disease with cavernous artery blood flow in erectile dysfunctional patients. Int J Impot Res 2001;13:100-3.

20. Palese MA, Crone JK, Burnett ALA. Castrated Mouse Model of Erectile Dysfunction. J Androl 2003;24:699-703.

21. Mulhall JP, Verma N, Deveci S, et al. Sildenafil citrate improves erectile function after castration in a rat model. BJU Int 2014;113:656-61.

22. Mulcahy JJ, Wilson SK. Current use of penile implants in erectile dysfunction. Curr Urol Rep 2006;7:485-9.

23. Mulligan T, Frick MF, Zuraw QC, et al. Prevalence of hypogonadism in males aged at least 45 years: the HIM study. Int J Clin Pract 2006;60:762-9.

24. Traish AM, Toselli P, Jeong SJ, et al. Adipocyte Accumulation in Penile Corpus Cavernosum ofthe Orchiectomized Rabbit: A Potential Mechanism for Venoocclusive Dysfunction in Androgen Deficiency. J Androl 2005;26:242-8.

25. Lindsey JPII, Lue TF, Shindel AW. The future of penile prostheses for the treatment of erectile dysfunction. Transl Androl Urol 2020;9:S244-51.

26. Collins T. Inflamação aguda e crítica. In: Robbins SL, T Collins, V Kuman, et al. editors. Robbins: Patologia estrutural e funcional. 6a edition. Rio de Janeiro: Guanabara Koogan, 2000:44-78.

27. Broughton G, Janis JE, Attinger CE. The basic science of wound healing. Plast Reconstr Surg 2006;117:12S-34S.
Cite this article as: Lima SVC, Chagas HM, Monteiro CCP, Ferraz-Carvalho RS, Albuquerque AV, Silva AA, Lira MMM, Vilar FO. Injectable semi rigid penile prosthesis: study in rabbits and future perspectives. Transl Androl Urol 2021;10(2):841850. doi: $10.21037 /$ tau-20-1128 